\title{
SOME INEQUALITIES FOR GENERALIZED FRACTIONAL INTEGRAL OPERATORS ON GENERALIZED MORREY SPACES
}

\author{
SATOKO SUGANO
}

Abstract. Boundedness of generalized fractional integral operators on generalized Morrey spaces and their related results were shown by many authors. We consider one of their results in a wider framework. Moreover, we show some inequalities for another operator on generalized fractional integrals on generalized Morrey spaces.

Mathematics subject classification (2010): Primary 26A33, 42B35; Secondary 42B25.

Keywords and phrases: Generalized fractional integral operator, generalized Morrey space, maximal function, Hölder's inequality.

\section{REFERENCES}

[1] D. R. AdAMS, A note on Riesz potentials, Duke Math. J., 42, 4 (1975), 765-778.

[2] F. Chiarenza And M. Frasca, Morrey spaces and Hardy-Littlewood maximal function, Rend. Mat. Appl., 7, 7 (1987), 273-279.

[3] D. Edmunds, V. Kokilashvili, And A. Menski, Bounded and compact integral operators, Math. Appl. vol. 543, Springer, 2002, Chapter 6.

[4] ERIDANI, H. Gunawan, On generalized fractional integrals, J. Indonesian Math. Soc. (MIHMI), 8, 3 (2002), 25-28.

[5] ERIDANi, H. Gunawan, AND E. NAKAI, On generalized fractional integral operators, Sci. Math. Jpn. 60, 3 (2004), 539-550.

[6] H. Gunawan, A note on the generalized fractional integral operators, J. Indonesian Math. Soc. (MIHMI), 9, 1 (2003), 39-43.

[7] K. Kurata, S. Nishigaki, And S. Sugano, Boundedness of integral operators on generalized Morrey spaces and its application to Schrödinger operators, Proc. Amer. Math. Soc., 128, 4 (2000), $1125-1134$.

[8] E. NAKAI, Hardy-Littlewood maximal operator, singular integral operators and the Riesz potentials on generalized Morrey spaces, Math. Nachr., 166 (1994), 95-103.

[9] E. NAKAI, On generalized fractional integrals, Taiwanese J. Math., 5, 3 (2001), 587-602.

[10] E. NAKAI, Generalized fractional integrals on Orlicz-Morrey spaces, Proceedings of International Symposium on Banach and Function Spaces (Kitakyushu, 2003), 323-333, Yokohama Publishers, Yokohama, 2004.

[11] E. NaKaI, Orlicz-Morrey spaces and the Hardy-Littlewood maximal function, Studia Math., 188 (2008), 193-221.

[12] E. NAKAI, private communication.

[13] P. A. Olsen, Fractional integration, Morrey spaces and a Schrödinger equation, Comm. Partial Differential Equations, 20 (1995), 2005-2055.

[14] J. PeEtre, On the theory of $\mathscr{L}_{p, \lambda}$ spaces, J. Funct. Anal., 4 (1969), 71-87.

[15] Y. SAWANO, S. SUGANO, AND H. TANAKA, Generalized fractional integral operators and fractional maximal operators in the framework of Morrey spaces, to appear in Trans. Amer. Math. Soc.

[16] Y. SAWANO, S. SUGANO, AND H. TANAKA, A note on generalized fractional integral operators on generalized Morrey spaces, Boundary Value Problems, Volume 2009, Article ID 835865, 18 pages, doi:10.1155/2009/835865. 
[17] S. Sugano And H. TANAKA, Boundedness of fractional integral operators on generalized Morrey spaces, Sci. Math. Jpn., 58, 3 (2003), 531-540.

[18] JinRong WAng, X. XIAng, W. Wei, AND QiAn Chen, The generalized Gronwall inequality and its application to periodic solutions of integrodifferential impulsive periodic system on Banach space, Journal of Inequalities and Applications, Volume 2008, Article ID 430521, 22 pages, doi:10.1155/2008/430521. 